\title{
KEAUSAN BANTALAN BOLA YANG DI IMPLANTASI ION TIN DENGAN PELUMASAN GREASE
}

\author{
Sinarep* \\ * Dosen Jurusan Teknik Mesin Universitas Mataram NTB, J1. Majapahit no 62 Mataram
}

\begin{abstract}
It has been conducted on the effect of ion implantation of TiN to wear ball bearings with grease lubrication. Ball bearing is one of the supporting components contained in the machine and the parts of a rotating element as found in automotive components. During the operation, this component causes the surface wear and vibration caused by continuous movement during loading.

Ion implanted TiN ball bearing at the time of 90 minutes, the energy of $100 \mathrm{keV}$ and current $10 \mu \mathrm{A}$ are ring inside the outer ring, and ball as the wear test samples. Tests carried out with 3 variations of wear load and $3100 \mathrm{rpm}$ shaft rotation. Grease is used to mark the torch. Then 3.9 grams of grease in then applied to the outer ring, inner ring and the ball.

The test results showed that the wear volume increased with increasing the load on ball bearing non-implantation with grease lubrication, while the ion implanted TiN almost no increase. Wear resistance increased in metal ion implanted TiN. It is characterized by decreasing in wear rate when compared with non-metal implants. And traces of scratches experienced a very significant reduction in metal ion implanted TiN.
\end{abstract}

Keywords: ball bearings, TiN ion implantation, wear, grease

\section{PENDAHULUAN}

Bantalan bola merupakan salah satu komponen pendukung yang terdapat pada mesin dan bagian-bagian peralatan yang berputar sebagaimana yang terdapat pada komponen otomotif. Selama beroperasi, komponen ini menyebabkan bagian permukaannya mengalami keausan dan getaran yang diakibatkan oleh gerakan terus-menerus selama pembebanan.

Berkaitan dengan penelitian komponen yang mengalami keasuan tersebut, perbedaan kekerasan bersifat sangat signifikan antara bola dan ring, yang sebenarnya kedua hal ini menimbulkan gesekan sehingga memunculkan kasus keausan berupa komponen yang lunak akan habis lebih dahulu dibanding yang keras. Untuk itu, kekerasan bahan atau komponen sangat perlu dinaikkan khususnya pada permukaan yang bergesek (Soekrisno, 2004).

Masalah yang timbul keausan akan menyebabkan umur pakai dari bantalan bola kemungkinan tidak lama, sehingga perlu diperlakukan lebih lanjut untuk meningkatkan ketahan aus. Hal tersebut dapat dilakukan dengan salah satu cara memberi lapisan tertentu dan dengan teknik tertentu pula. Teknik pelapisan yang dipilih pada penelitian ini adalah implantasi ion TiN dengan waktu 90 menit dan energi 100 $\mathrm{KeV}$. Dalam hal ini, bagian yang dilapisi adalah ring dalam, ring luar dan bola dengan pelumasan grease. Dengan penelitian ini, diharapkan akan terlihat perubahan sifat-sifat yang diperoleh sesuai dengan parameter pelapisan seperti dosis, energi, durasi dan ketebalan lapisan yang dipilih. Penelitian ini menggunakan parameter variasi beban, dan waktu putaran dengan pelumasan grease.

Penelitian ini, diharapkan nantinya dapat memberikan kontribusi positif pada pengembangan ilmu pengetahuan dan teknologi, terutama pada ilmu rekayasa permukaan bahan dan mampu memberikan wawasan yang komprehensif bagi para ahli rekayasa permukaan.

Implantasi ion titanium dan acetylene pada permukaan baja bearing AISI 440 menghasilkan perbaikan yang signifikan terhadap ketahanan aus dan gesekan. Hal ini sangat potensial untuk memperbaiki sifat permukaan dan umur pakai bantalan bola (Zeng, dkk, 2003). Kerusakan akibat aus pada permukaan dapat diturunkan dengan meningkatkan kekerasan, yang salah satunya dengan implantasi ion TiN. Metode implantasi ion merupakan proses yang sangat menguntungkan dalam merubah sifat-sifat permukaan bahan, yang parameter-parameternya seperti jenis ion, energi, rapat arus dari ion, jumlah dosis yang diberikan serta sudut penembakan dapat diatur dan disesuaikan secara presisi (Moller dan Mukherjee, 2002). Bahan TiN/AlN menghasilkan lapisan yang sangat keras, kestabilan kimia yang tinggi dan adesi pada benda yang baik sampai pada suhu $500^{\circ} \mathrm{C}$, sedangkan pada suhu lebih dari $700^{\circ} \mathrm{C}$ terjadi oksidasi (Yao dkk., 2004). Di samping itu, pada bahan bantalan seperti inconel 718 proses plasma CVD yang dikombinasikan dengan ion implantasi, hasilnya memperlihatkan bahwa implantasi ion telah berhasil membentu film diamond like carbon (DCL) yang keras, dengan adesif sangat kuat sehingga memiliki ketahanan 
terhadap gesekan yang tinggi (Kenji, dkk, 2004).

Pada proses implantasi ion TiN, penambahan bahan yang diberikan akan bereaksi bersama-sama dengan bahan yang diimplantasi. Di sini ion-ion yang berenergi tinggi akan dicangkokkan ke bahan padat dengan bantuan ekselerator ion sehingga terjadi penyusupan ion dan terbentuk senyawa ion dopan dengan atom target yang keras. Pada implantasi ion ada beberapa pengertian yang perlu diketahui yakni dosis ion, jangkauan ion, dan kerusakan bahan akibat radiasi (Ryessel, dkk,1986).

Penggunaan energi tinggi (sampai 100 $\mathrm{keV}$ ) pada implantasi ion menyebabkan ion target menembus masuk ke bawah permukaan substrat sehingga tidak terjadi sputtering. Hal ini

\section{Metodologi Penelitian \\ 1. Bahan Penelitian}

Dalam penelitian ini digunakan beberapa bahan yaitu bantalan bola kode ASB dengan tipe 20 BSW 01, serbuk TiN , Alkohol, Grease dengan merek obor

\section{Alat yang Digunakan}

Mesin implantasi ion , Ultrasonik cleaner, Digital Tachometer, Alat uji keausan, untuk menguji keausan bantalan bola, Mikroskop optic, untuk memeriksa struktur mikro pada ring

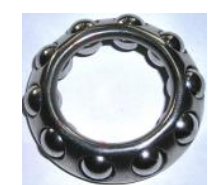

$\mathbf{a}$

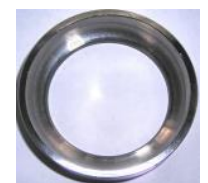

$\mathbf{b}$

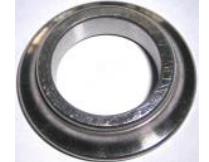

c
Gambar 3. Bantalan bola dengan dua arah pembebanan (a. ring luar, b. Ring dalam, c. Bola dan sangkar, d. Potongan bantalan bola)

\section{Cara Penelitian}

\section{a. Proses Implantasi Ion TiN}

Benda uji bantalan bola sebanyak 30 buah, yang masing-masing terdiri dari 15 buah yang diimplantasi ion TiN dan 15 buah tidak diimplantasi ion. Serbuk TiN sebagai target diletakkan pada katoda dan benda uji ring dan bola diletakkan pada anoda. Selama peroses pemvakuman, temperatur kontrol diatur sesuai suhu yang diteliti. Setelah temperatur dan

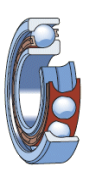

d terjadi karena ion target tersebut terdeposisi jauh ke bawah permukaan substrat dan ion target tersebut terjebak ke dalam substrat. Implantasi ion mempengaruhi struktur permukaan material melalui dua cara yaitu: 1) dengan masuknya bahan implan maka larutan padat (solid solution) atau paduan bisa terbentuk. 2) dengan kerusakan radiasi (radiation damage) tempat terbentuknya cacat kisi akibat perpindahan atom-atom yang bertumbukan dengan ion (Hutchings, 1995).

Adapun tujuan penelitian ini adalah mengetahui pengaruh laju keausan batalan bola terhadap beban dan jarak dengan pelumasan grease, baik tanpa implantasi maupun dengan implantasi ion TiN

dan bola. Electronic inverters, untuk mengatur putaran motor listrik

\section{Parameter Penelitian}

Bantalan bola yang digunakan dengan tipe angular contact ball bearing dan no seri 20BSW01 yang mempunyai spesifik sebagai berikut diameter dalam $20 \mathrm{~mm}$, diameter luar 52 $\mathrm{mm}$, diameter bola $10 \mathrm{~mm}$, lebar $15 \mathrm{~mm}$, bahan ring dan bola baja paduan dan masa jenis 7,8 $\mathrm{g} / \mathrm{mm}^{2}$

pemvakuman tercapai, sumber tegangan tinggi DC dihubungkan dengan terminal katoda dan anoda.. Proses pendeposisian ini berlangsung pada tekanan sekitar $6.10^{-2}$ torr $\left(1 \mathrm{~Pa}=7,8 \times 10^{-3}\right.$ torr), suhu $250^{\circ} \mathrm{C}$, selama 1 jam (Mudjijana, 2004). Impalantasi ion TiN dengan waktu 90 menit dan energi $100 \mathrm{keV}$. Sedangkan untuk spesimen uji laju keausan bantalan bola bagian ring dan bola dipisahkan terlebih dahulu, karena yang akan di implantasi ion TiN bagian ring luar, ring dalam dan bola. Bagian-bagian tersebut dibersihkan dengan cairan alkohol dengan alat ultrasonik cleaner, lalu kemudian diimplantasi ion TiN. 


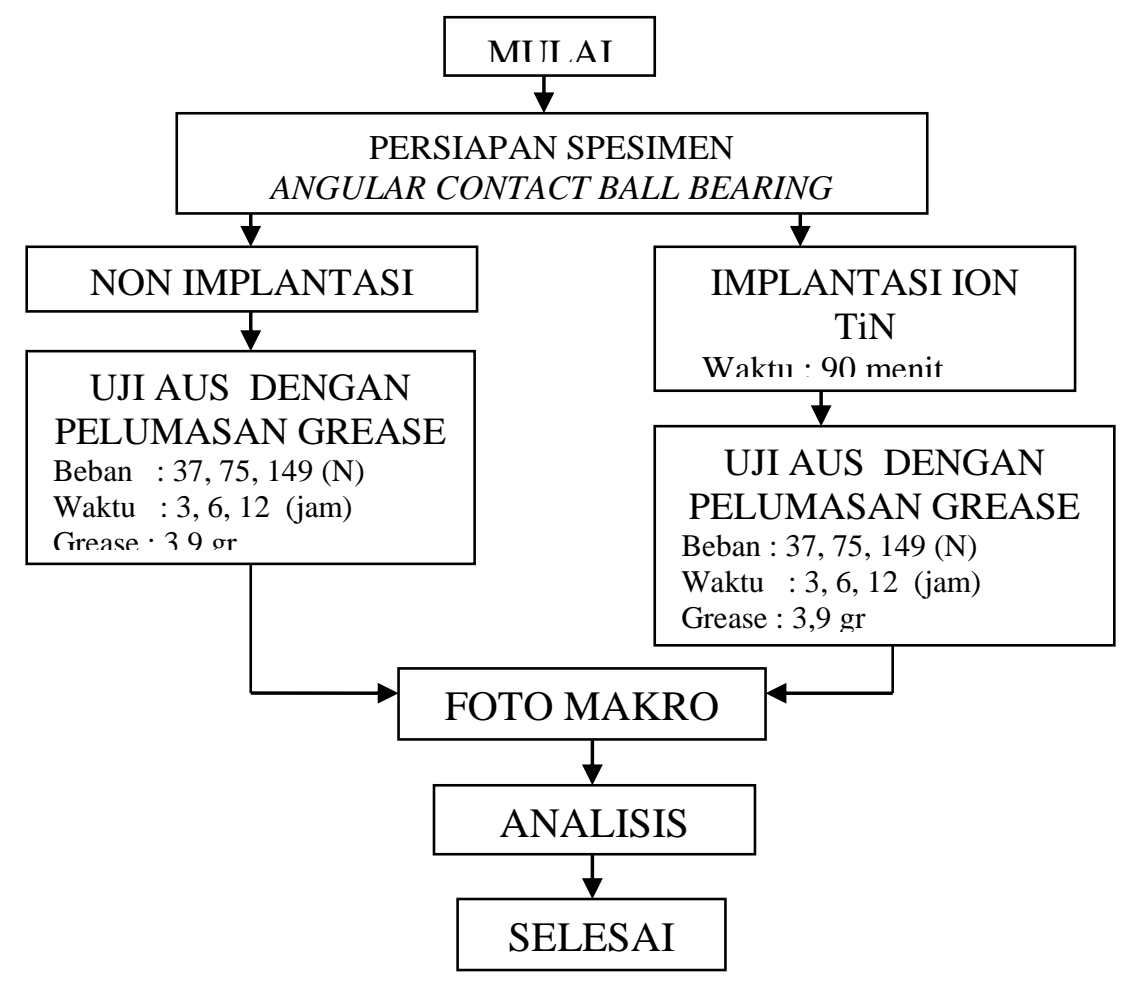

Gambar 5. Diagram alur penelitian

\section{b. Keausan}

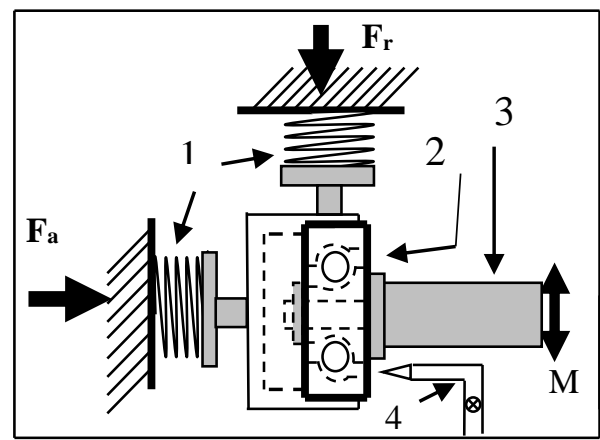

1. Pegas

2. Bantalan bola

3. Poros

4. Nozzel

$F_{\mathrm{a}}$. Beban aksial

$\mathrm{F}_{\mathrm{r}}$. Beban radial

M. motor

\section{Gambar 4. Skema Alat Uji Keausan}

Bantalan bola yang sudah diimplantasi maupun yang belum selanjutnya diuji ketahanan keausan dengan pelumasan grease dengan mennggunakan alat seperti gambar 4. Kemudian ditentukan kedudukan beban penyeimbang dengan lengan beban sehingga ujung pin aksial dan radial dalam kondisi berhubungan dengan permukaan bantalan bola meskipun tanpa beban. Keseimbangan ini diukur dengan waterpass. Beban aksial dan radial dipasang pada masingmasing ujung lengan dengan cara memutar handel dan menekan pegas sehingga ujung kontak pin menekan permukaan bearing dan mendapatkan gaya atau beban, adapun variasi beban adalah 5,10 dan $20 \mathrm{~kg}$

Pengujian keausan pelumasan grease, terlebih dahulu mesin dihidupkan sementara grease ditimbang dahulu yang disesuaikan dengan kebutuhan bantalan bola yaitu 3,9 gr. Kemudian grease dipoleskan pada ring luar, ring dalam dan bola. Bantalan bola dipasang pada mesin uji keausan dan mesin dijalankan dengan putaran poros $3100 \mathrm{rpm}$. Setiap variasi beban dan waktu, diperoleh data yaitu berat keausan bantalan bola pada masing-masing perlakuan. Adapun data yang bisa diperoleh pada pengujian ini adalah pengurangan berat. Kemudian data tersebut diolah menjadi nilai laju keausan dengan pelumasan grease melalui persamaan 4 dan 5 . Pengujian ini didapatkan gerafik hubungan laju keausan dengan jarak dan demikian juga untuk volume keausan. 


\section{Hasil Penelitian Dan Pembahasan \\ 1. Hasil Pengujian Keausan dengan \\ Pelumasan Grease}

a. Volume Keausan dengan Pelumasan Grease

Gambar 6 mengilustrasikan suatu grafik hubungan volume keausan terhadap jarak dengan pelumasan grease pada putaran poros $3100 \mathrm{rpm}$. Pada grafik tersebut terlihat secara jelas bahwa volume keausan non implantasi mengalami peningkatan dengan bertambahnya beban dan jarak. Volume aus tertingggi terdapat pada non implantasi dengan beban $149 \mathrm{~N}$ dan jarak 252433 m yakni $1,153846 \mathrm{~mm}^{3}$, dan yang terendah terjadi pada implantasi ion TiN dengan beban 37 $\mathrm{N}$ sejauh $63108 \mathrm{~m}$ yakni $0,333333 \mathrm{~mm}^{3}$. Kenaikan ini bisa dilihat jelas pada ring luar dan sangkar sementara pada ring dalam dan bola kenaikan volume keausan yang signifikan mulai terlihat pada jarak terjauh yakni sekitar 252433 m.

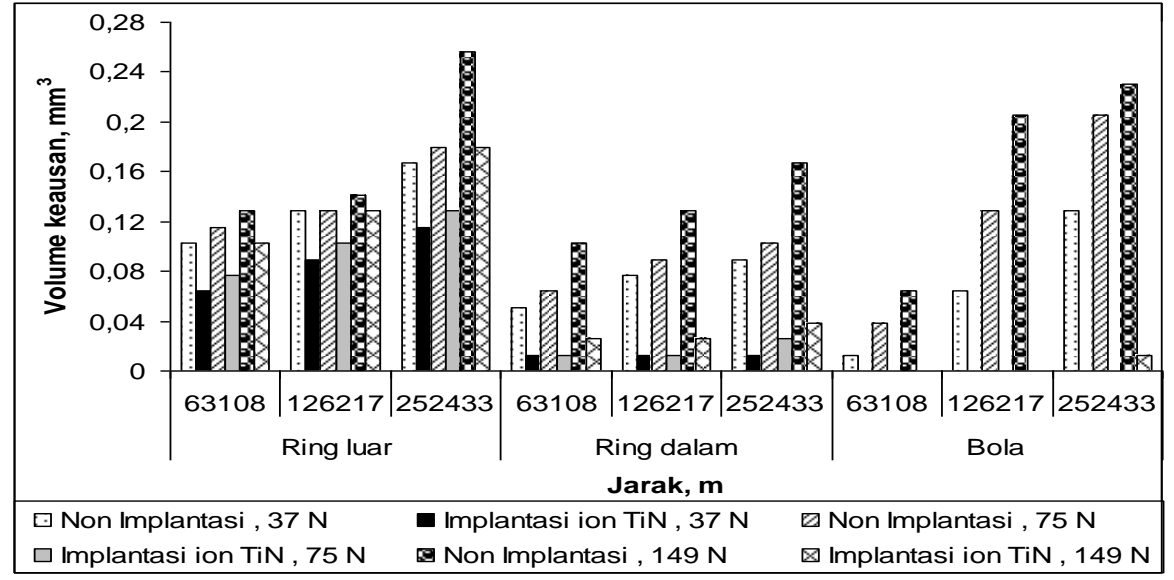

Gambar 6. Grafik hubungan volume keausan terhadap jarak pada putaran poros 3100 rpm

Untuk bantalan bola yang diimplantasi ion TiN volume keausan sangat rendah dibanding yang non implantasi. Volume keausan pada bola masih $0 \mathrm{~mm}^{3}$ (tidak terlihat pengurangan beratnya) dan akhirnya mulai terlihat pada beban $149 \mathrm{~N}$ dengan jarak $252433 \mathrm{~m}$, yaitu $1 \times 10^{-4} \mathrm{~mm}^{3}$ (Gambar 8). Hal ini disebabkan karena kemampuan alat ukur tidak memadai. Sementara pada ring luar dan ring dalam sudah terlihat volume keausannya meskipun masih relatif rendah, terutama pada ring dalam kenaikan volume keausannya hampir konstan. Sesuai dengan yang diharapkan sebelumnya, dengan pengurangan berat yang sangat rendah ini, bahan yang diimplantasi akan meningkat kekerasannya dan mengurangi volume keausan bahan.

\section{b. Laju Keausan dengan Pelumasan Grease}

Pada jarak tempuh yang sama laju keausan meningkat drastis dengan bertambah beban pada non implantasi dan kenaikan tertinggi terjadi pada beban $149 \mathrm{~N}$ dengan jarak $63108 \mathrm{~m}$ yaitu
$1,0767 \times 10^{-5} \mathrm{~mm}^{3} / \mathrm{m}$ dan yang terendah terjadi pada implantasi ion TiN dengan beban $37 \mathrm{~N}$ sejauh $252433 \mathrm{~m}$ yakni $1,72678 \times 10^{-6} \mathrm{~mm}^{3} / \mathrm{m}$. Sedangkan yang diimplatasi ion TiN peningkatan laju keausan tidak terlalu signifikan. Kemudian pada beban yang sama laju keausan menurun dengan bertambahnya jarak pada implantasi ion TiN dan penurunan terjadi pada jarak terjauh. Hal ini disebabkan karena grease masih berfungsi dengan baik melumasi bantalan bola. Grafik laju keausan pada ring dalam dan bola menunjukkan bahwa kondisi implantasi ion TiN memberikan efek yang lebih baik yaitu menurunkan nilai laju keausan dibandingkan non implantasi pada beban yang sama dan jarak yang sama pula. Akan tetapi pada ring luar penurunan laju keausan tidak signifikan seperti ring dalam dan bola pada kondisi implantasi ion TiN. Benda yang bergesek akan mengalami keausan; bahan yang lunak akan terkikis habis lebih dahulu dibanding bahan yang keras. 


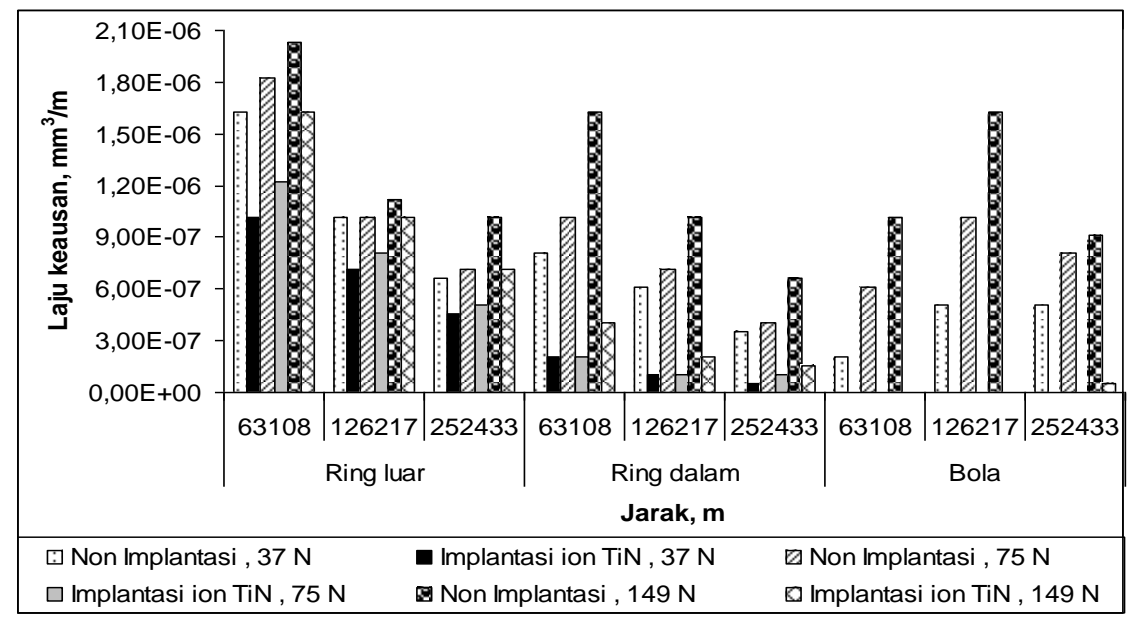

Gambar 7. Grafik hubungan laju keausan terhadap jarak pada putaran poros $3100 \mathrm{rpm}$

Hasil pengamatan pengujian yang memperlihatkan laju keausan non implantasi relatif meningkat pada penambahan beban dan menurun apabila adanya penambahan jarak tempuh. Sedangkan yang diimplantasi ion TiN laju keausan hampir konstan dengan bertambahnya beban. Peningkatan non implantasi dengan bertambahnya beban ini bisa terjadi karena gesekan antara partikel-partikel logam yang ada di permukaan bantalan bola. Hal ini terjadi disebabkan adanya film tipis dari grease yang sudah hancur dan kekasaran permukaan bertambah. Kehadiran film tipis ini memang sangat mempengaruhi ketahanan keausan; akan tetapi kontak gesekan dan degradasi mempercepat penghancuran film tersebut. Kontaminasi akan menyebabkan lemahnya ikatan antara permukaan bantalan bola, sehingga akan menurunkan kekuatan geser antara permukaan.

\section{Foto Makro dengan Pelumasan Grease}

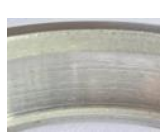

A1

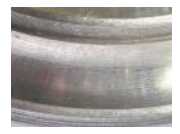

A2

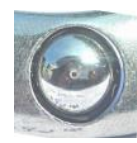

A3

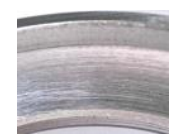

B1

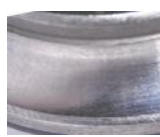

B2

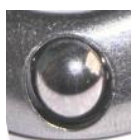

B3

Gambar 8. Foto makro bantalan bola non Implantasi dengan pelumasan grease

A. Bantalan bola dengan beban $37 \mathrm{~N}$ dan jarak $63108 \mathrm{~m}$,

B. Bantalan bola dengan beban $149 \mathrm{~N}$ dan jarak $252433 \mathrm{~m}$,

( 1. ring luar. 2 ring dalam 3. bola dan sangkar)

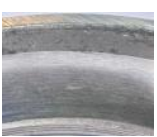

C1

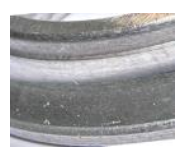

$\mathrm{C} 2$

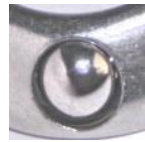

C3

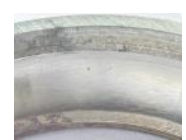

D1

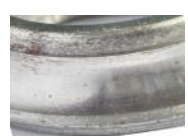

D2

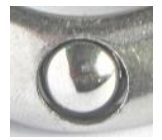

D3

Gambar 9. Foto makro bantalan bola diimplantasi ion TiN dengan pelumasan grease

C. bantalan bola dengan beban $37 \mathrm{~N}$ dan jarak $63108 \mathrm{~m}$

D. bantalan bola dengan beban $149 \mathrm{~N}$ dan jarak $252433 \mathrm{~m}$.

( 1. ring luar. 2 ring dalam 3. bola dan sangkar)

Foto makro non implantasi menunjukkan goresan-geresan kecil dan merata; sementara, foto makro yang diimplantasi ion TiN goresan tidak begitu terlihat. Ini berarti tingkat kerusakan diimplantasi yang terjadi jauh lebih ringan. Tingkat kerusakan bantalan bola yang terjadi menunjukkan bahwa proses implantasi ion TiN telah meningkatkan ketahanan aus atau nenurunkan laju keausan. Dengan bertambahnya jarak, kesempatan perkembangan goresan tersebut akan berkurang yang disebabkan film dari grease masih berfungsi dengan baik 


\section{Kesimpulan}

Volume keausan mengalami kenaikan dengan bertambah beban pada bantalan bola non implantasi dengan pelumasan grease, sedangkan yang diimplantasi ion TiN hampir tidak terjadi kenaikan. Bahkan pada bola masih $0 \mathrm{~mm}^{3}$. Ketahanan aus akan meningkat pada logam yang diimplantasi ion TiN. Hal ini ditandai dengan penurunan laju keausan apabila dibandingkan dengan logam yang non implantasi. Serta jejak goresan akan mengalami pengurangan yang sangat signifikan pada logam yang diimplantasi ion TiN.

DAFTAR PUSTAKA

Hutchings, I.M., 1992, "Tribology Friction and Wear of Engineering Materials", London.

Kenji, F., Koichiro, W., Kazuo, U. and Tadashi, S., 2004, "Preparation of Highly Adhesive Diamond-Like Carbon Films by Plasma CVD Combined With Ion Implantation", IHI Engineering Review, Vol. 37, No 1.

Moller, W. and Mukherjee, S., 2002, "PlasmaBased Ion Implantation", Current Science, Vol. 83, No. 3.

Mudjijana, Sujatmoko, Suyitno, dan Susanto, 2001, "Deposition Lapisan Tipis Tintanium Nitrida pada Subtrat Aluminium dengan Teknik Sputtering DC”, Proseding Seminar Nasional Pengembangan Keramik Teknologi dan Aplikasinya, Serpong, Indonesia.

NSK, 2003, "Rolling Motion \& Rolling Element", NSK Co. Ltd. Singapore.

Rizal, M. dan Bendiyasa, I.M., 2004, "Forum Teknik".

Ryssel, Heiner, Rugi, and Ingolg, 1986, "Ion Implantation", John Willey and Sons. New York.

Soekrisno, 2004, "Perbandingan Kekerasan Struktur Mikro dan Komposisi kimia Bantalan Bola Produk Jepang dan China", Jurnal Mesin dan Industri, Vol. 1, No. 3, Hal. 9-14.

Yao, S.H., Kao, W.H., Su, Y.L., Liu, T.H., 2004, "Effect of Periods on Wear Performance of TiN/AlN Superlattice Flims", Material Science and Engineering A 392, pp, 380-385.

Zeng, Z.M., Tian, X.B. and Chu, P.K., 2003, "Ion Enhanced Deposition by Dual Titanium and Acetylene Plasma Immersion Ion Implantation", Journal Vacum Science Tecnology, A 21. 